\title{
Formação de professores de Geografia e História em Portugal: uma década de investigação-ação pós Bolonha
}

\author{
Glória SOLÉ \\ Elsa PACHECO \\ Laura SOARES
}

\section{Datos de contacto: \\ Glória Solé \\ Universidade do Minho \\ gsole@ie.uminho.pt \\ Elsa Pacheco \\ Universidade do Porto \\ elsap@letras.up.pt \\ Laura Soares \\ Universidade do Porto \\ lauras@letras.up.pt}

Recibido: 08/07/2020

Aceptado: 16/11/2020

\section{RESUMO}

Trinta anos decorridos sobre a formação de professores no contexto dos Mestrados em Ensino de Geografia e/ou História no 3o ciclo do Ensino Básico e Secundário e uma década após a entrada em vigor do modelo educativo implementado no quadro do processo de Bolonha, propõe-se uma reflexão sobre os temas de investigação-ação que foram alvo dos Relatórios de Estágio apresentados nas Universidades Portuguesas onde existe este 2o Ciclo de Estudos. Consultando os respetivos Repositórios Científicos, procede-se inicialmente a uma avaliação das principais palavras utilizadas nos títulos dos relatórios das duas áreas disciplinares, pormenorizando depois a nossa análise sobre os trabalhos desenvolvidos nas Universidades do Minho e do Porto, a partir da sua categorização em temáticas devidamente especificadas através de descritores elaborados para o efeito. Concluímos que o enfoque temático se direciona mais para o desenvolvimento de competências centradas em valores ancorados na vida real dos alunos e menos na aposta em assuntos de base tecnológica, como seria de esperar.

PALABRAS CLAVE: Ensino e educação; Geografia e História; Estágio Supervisionado; Investigação-ação; Profissionalismo docente. 


\title{
Geography and History teachers training in Portugal: a decade of action-research after Bologna Process
}

\begin{abstract}
Thirty years after the beginning of teacher training in the context of Masters in Geography and/or History Teaching in the 3rd cycle of Basic and Secondary Education and a decade upon the education model implemented by Bologna process, a reflection is proposed here on the action- research themes of the Internship Reports presented in Portuguese Universities where exists this 2 nd Cycle of Studies. After consulting the respective Scientific Repositories, an initial assessment is made of the main words used in the report titles of the two subject areas, detailing after our analysis of the works developed at the Universities of Minho and Porto, based on their categorization into themes, duly specified through descriptors prepared for this purpose. We conclude that the themes of the reports are directed more towards the development of competencies centered on values anchored in the real life of students and less on technology-based subjects, as we expected.
\end{abstract}

KEYWORDS: Teacher training; Geography and History; Supervised internship; Actionresearch; Teacher professionalism; Portugal.

\section{Introdução}

A preocupação com a formação de professores que irão exercer a sua profissão junto de um público constituído, maioritariamente, por jovens, não é de hoje, nem cabe apenas no espaço disciplinar da Geografia ou da História. De facto, o encolhimento do tempo de transição geracional decorrente da velocidade com que se processam as mudanças socioculturais mediadas pela vertigem tecnológica, tem feito com que, em menos de uma década, meios e conteúdos de ensino e aprendizagem mudem rapidamente, traduzindo-se na evidente décalage formativa, de base tecnológica, entre professores frequentemente designados 'imigrantes digitais' - e alunos - 'nativos digitais' (Faria, 2004; Prensky, 2001; Wang, Hsu, Campbell, Coster, \& Longhurst, 2014). Dito de outra forma, os tempos longos de transição na evolução das economias industriais dos séculos XVIII, XIX e XX (indústrias $1.0,2.0$ e 3.0 , respetivamente), com intervalos de adaptação de cerca de um século, dão lugar, agora, com meio século de distância face aos desenvolvimentos de meados do século passado, aos sistemas cibernéticos das redes e da inteligência artificial - a 
indústria 4.0 - cujas componentes (big data, simulação, realidade aumentada, nuvem, segurança cibernética, entre muitas outras), para a maioria dos profissionais de educação, nada têm a ver com o que conhecem dos sistemas produtivos tradicionais (Akçayır \& Akçayır, 2017; Darmaji, Kurniawan, Astalini, Lumbantoruan, \& Samosir, 2019; Kirner \& Zorzal, 2005; Lase, 2019; West, 2012). No entanto, é provável que as diferenças entre nativos e imigrantes digitais frequentemente abordadas em estudos científicos - sejam exageradas, sugerindo vários autores que não devem ser descritas em termos extremos (Guo, Dobson, \& Petrina, 2008; Kirschner \& De Bruyckere, 2017; Salajan, Schönwetter, \& Cleghorn, 2010). Na verdade, as transformações impostas ao sistema educativo pela pandemia do Covid-19 demonstram tal facto, sendo manifesta a capacidade de adaptação dos professores às tecnologias digitais, enquanto os jovens alunos, que sempre 'viveram no digital', nem sempre revelam as competências julgadas adquiridas neste domínio. Como salientam Zhou, Wu, Zhou, \& Li (2020, p.516), refletindo sobre a educação online na China durante a pandemia, "(...) some students, due to lack of selfcontrol and self-learning ability, lacked face-to-face teacher or even parental supervision, online learning became a form, and the autonomous learning effect was not satisfactory".

Efetivamente, se a utilização das Tecnologias de Educação e Comunicação (TIC) são um dos temas preferenciais dos estudos científicos atuais, assim como atraem a preferência de grande parte dos estudantes, o seu impacto positivo não ocorre automaticamente e depende muito de como os professores usam as TIC nas suas aulas (Kozma, 2003). Assim, é importante que os professores adquiram mais conhecimentos e competências neste domínio, de forma a que possam avaliar de forma sustentada 'porquê, quando e como' devem introduzir as tecnologias digitais nas suas sessões letivas (Carver, 2016; Ertmer, Ottenbreit-Leftwich, Sadik, Sendurur, \& Sendurur 2012; OttenbreitLeftwich Glazewski, Newby, \& Ertmer, 2010). Consequentemente, hoje mais do que nunca, os docentes devem perspetivar a sua carreira profissional numa lógica de formação contínua para que possam ir ao encontro dos seus principais interlocutores - os alunos (Caena, 2011; Leite, 2005; de Vries, Jansen, \& van de Grift, 2013).

Mas independentemente das reflexões expostas, é importante não esquecer que a educação se deve centrar no cuidado e atenção sobre os conhecimentos, capacidades e atitudes dos alunos, um imperativo pedagógico para a construção de procedimentos capazes de promover a comunicação entre docentes e discentes e entre estes e a sociedade que os rodeia (d'Oliveira Martins et al., 2017).

Neste quadro, além da universalidade prevista no objetivo 4 da 
Agenda 2030 de Desenvolvimento Sustentável (ONU, 2016: 8-9) - sobre a necessidade de assegurar uma educação baseada em princípios de inclusão, qualidade e equidade, assim como garantir oportunidades de aprendizagem ao longo da vida -, também em 2016 se destacaram outros diplomas internacionais como o Projeto Educação 2030 (OECD, 2016) e Repensar a Educação (UNESCO, 2016), confirmando, em conjunto, a emergência e afirmação de perspetivas de educação menos prescritivas e mais 'orientativas', fortemente humanistas, centradas na aprendizagem colaborativa e na autonomia e flexibilidade curricular.

Em Portugal as alterações preconizadas refletem-se em documentos legislativos e na produção de referenciais de apoio à implementação de uma 'nova educação'. Com efeito, desde O Perfil dos Alunos à Saída da Escolaridade Obrigatória (Despacho nº478/2017), passando pela Estratégia Nacional de Educação para a Cidadania (DGE, 2017a), as Aprendizagens Essenciais (DGE, 2017b) e culminando com a promulgação dos Decretos-Lei n. ${ }^{\circ} 54 / 2018$, de 6 de julho (alterado pela Lei n. ${ }^{\circ} 116 / 2019$, de 13 de setembro) - que define o regime jurídico da educação inclusiva - e n. ${ }^{\circ} 55 / 2018$, de 6 de julho - estabelecendo o currículo dos ensinos básico e secundário, os princípios orientadores da sua conceção, operacionalização e avaliação das aprendizagens -, observa-se um esforço conjugado de mudanças que implicam uma reflexão sobre os desafios que se colocam a todo o sistema e agentes educativos. Estes desafios, na nossa opinião, exigem uma mudança na postura das instituições de ensino e dos professores apelando sobretudo a um trabalho colaborativo interpares, de forma a que cada Escola - considerando o perfil das competências dos alunos no final da escolaridade obrigatória, o regime jurídico da educação inclusiva e a margem de 'liberdade' conferida pela autonomia e flexibilidade curricular - seja capaz de construir respostas adequadas e eficazes à aprendizagem de todos os alunos, através da definição das ações educativas a operacionalizar de acordo com as suas necessidades especificas (cognitivas e emocionais), as particularidades do seu contexto socioeconómico e cultural e os recursos disponíveis que podem mobilizar.

Face a todas estas alterações, cada vez mais frequentes no sistema educativo - porque assim o exige a velocidade da mudança individual e coletiva numa 'aldeia global' tecnologicamente mediada - e admitindo que de nada adiantam imperativos teóricos se não ocorrer aplicação, é pertinente observar se as práticas docentes estão (ou não) a acompanhar as alterações preconizadas, nomeadamente no contexto da formação inicial de professores, ponto de partida para a profissionalização e suscetivel de promover nos futuros docentes atitudes e competências que permitam a sua adaptação a uma escola 
que todos os dias coloca novos desafios (Perrenoud, 1999). Mesmo apesar de sabermos que nem sempre há concordância entre a formação inicial e o desempenho posterior, porque as rotinas escolares, não raras vezes, sobrepõem-se aos esforços de inovação normalmente fomentados nessa fase (Claudino, 2011).

Considerando que os professores estagiários constituem uma ponte estratégica de ligação entre a universidade e as escolas, ligação esta acompanhada de perto por docentes do ensino superior e do ensino básico e secundário, então a análise dos trabalhos e reflexões que se desenvolvem durante o estágio constituem uma excelente ferramenta que pode contribuir para a ponderação das práticas educativas. Dito de outra forma, os Relatórios de Estágio (RE) expressam as experiências pedagógicas dos jovens docentes (filtradas por um corpo teórico adequado, inerente ao ensino supervisionado), resultando do seu projeto de investigação-ação de iniciação à prática profissional. É, de facto, este o momento em que o estagiário confronta o conhecimento teórico com a sua experiência, através dos dados empíricos recolhidos em ambiente escolar.

Assim, consideramos que o estágio da Iniciação à Prática Profissional (IPP), ao pressupor o desenvolvimento de trabalhos que envolvem diferentes gerações (Orientadores - científicos e os cooperantes, Professores Estagiários e os Alunos), trabalhos estes vertidos em RE's realizados com base num processo de investigaçãoação onde a teoria converge com a prática, resultante do Projeto de Intervenção Pedagógica Supervisionada (PIPS) que exige certo domínio de procedimentos afetos à construção e implementação de instrumentos de recolha de dados sobre os contextos de intervenção e as práticas pedagógicas desenvolvidas, e à análise e reflexão das evidências encontradas (Cachinho, 2002; Melo, 2015; Vieira et al., 2013), constitui um espaço fértil de informação, não só para identificar quais as preocupações recentes no âmbito do ensino e educação geográfica e histórica em Portugal objetivo principal desta investigação - como também verificar a existência, ou não, de convergência temática com a estrutura curricular dos ciclos de estudo em questão e as linhas orientadoras atuais da educação.

Neste sentido, definimos um percurso metodológico que se inicia com a recolha de informação sobre os temas dos RE de Geografia e de História realizados no período pós-Bolonha, através da consulta dos respetivos títulos registados nos repositórios das universidades portuguesas que conferem o grau de mestre, com profissionalização docente, nestas duas áreas disciplinares. A partir deste levantamento, procede-se a um breve tratamento estatístico das palavras mais utilizadas - de forma a extrapolar algumas leituras sobre as questões 
de ensino-aprendizagem privilegiadas durante esta década de formação de professores - que servirá de suporte a uma leitura mais fina sobre os relatórios de Geografia e História desenvolvidos nas Universidades do Minho e do Porto. Para este último exercício, utilizaremos uma grelha de categorização temática com os respetivos descritores para podermos validar a apreciação dos registos anteriores.

Para que se possa compreender melhor o contexto do sistema educativo em que se desenvolveram os relatórios de estágio que deram lugar a esta reflexão, previamente à análise e discussão dos resultados obtidos apresentamos um breve enquadramento da formação de professores de Geografia e História em Portugal, enfatizando o quadro da sua evolução no período pós-Bolonha.

\section{Percursos e perspetivas atuais da formação de professores de Geografia e História em Portugal}

Com uma matriz de base disciplinar, a formação de professores em Portugal marcou, durante muito tempo, a reprodução do conhecimento académico suportada em métodos de lecionação através da transmissão do saber. Embora se mantenha este modelo em alguns setores mais conservadores, certo é que a racionalidade prática tem vindo a consolidar a importância do aluno na construção do conhecimento, o que exige uma formação diferente, que valorize o conhecimento científico, mas agora numa perspetiva interpretativa, problematizadora e reflexiva.

A estrutura curricular de formação de professores de Geografia e de História surge na sequência do modelo de formação integrada de finais dos anos 80 do século XX no qual, desde o $3^{\circ}$ ano da licenciatura, os estudantes que quisessem enveredar pela via ensino, deveriam frequentar unidades curriculares de formação educacional geral e específica da área disciplinar, regulamentadas por portarias específicas a cada uma das universidades (Portarias n. ${ }^{\circ} 844 / 87$ de 28 de outubro, $850 / 87$ de 3 de novembro, 852/87 e 853/87 de 4 de novembro, relativas às universidades de Coimbra, Porto e Lisboa - 'clássica' e Nova) de acordo com a Lei de Bases do Sistema Educativo em vigor (Lei n. ${ }^{\circ} 46 / 86$ de 14 de Outubro) e do capítulo III do Decreto-Lei n. ${ }^{\circ}$ 316/83 de 2 de Julho. Nas Universidades de Aveiro, Évora e Minho as licenciaturas em ensino, tinham uma estrutura curricular que integrava desde os primeiros anos da formação unidades curriculares de formação educacional geral e específica da área disciplinar e estágio integrado (Decretos Regulamentares n.os 37/78, 38/78 e 39/78, de 25 de Outubro). 
Nas universidades clássicas, como o grau de licenciado era obtido em quatro anos, o estágio monodisciplinar decorria no $5^{\circ}$ ano, em escola do $3^{\circ}$ ciclo do ensino básico e secundário, durante um ano letivo. A cada estagiário eram atribuídas duas turmas e, além destas atividades, os jovens professores frequentavam, também, uma outra unidade curricular na unidade orgânica de acolhimento (Mesquita \& Machado, 2017; Santos \& Martins, 2016; Silva, 1988).

Em vigor durante quase 20 anos (de 1987 a 2005), esta formação integrada conhece uma ligeira mudança de 2005 a 2008, sendo exigida aos licenciados a inscrição no Curso de Especialização em Ensino, no âmbito do qual se realizava o estágio, mas agora em turmas atribuídas aos docentes das escolas - seus orientadores (Martins, 2012).

Nas universidades de Aveiro, Évora e Minho, a formação académica em ensino era integrada nas licenciaturas de Geografia e História, nessa altura era já de cinco anos, e o último ano era de estágio.

O modelo de formação inicial de professores em Geografia e História sofreu alterações na sequência da entrada em vigor do processo de Bolonha (Decreto-Lei $n^{\circ} 43 / 2007$ de 22 de fevereiro), que passa a reconhecer habilitação para a docência conferindo o grau académico de mestre. No âmbito deste decreto, constituiu-se o $2^{\circ}$ ciclo de estudos em Ensino da História e Geografia, no $3^{\circ}$ Ciclo do Ensino Básico e no Ensino Secundário (MEHG), ou seja, a formação de professores nestas áreas disciplinares, desde 2008/09 passa a fazer-se de forma conjunta com uma duração de dois anos letivos.

Embora o preâmbulo do Decreto-Lei $n^{\circ} 43 / 2007$ tenha deixado clara a importância do conhecimento disciplinar de base para a formação de professores, de facto o acesso ao MEHG passa a fazer-se com, apenas, 126ECTS numa das áreas e 54ECTS na outra, ou seja, é por demais evidente que há contradição entre o princípio e a sua aplicação em termos de critérios de acesso - em nenhuma das disciplinas a formação de base alcançaria os 180ECTS e uma delas ficava-se pelos 54ECTS.

Em termos de organização do plano de estudos, o Decreto de Lei não deixava grande margem para as Universidades optarem pela distribuição das unidades curriculares pelas diferentes áreas, estabelecendo que 25\% dos ECTS deviam corresponder à Formação Educacional Geral (FEG), cabendo igual percentagem às Didáticas Específicas (FDE). A Iniciação à Prática Profissional (IPP) ocupava $40 \%$ da carga total de créditos do ciclo de estudos, cabendo, apenas, $5 \%$ à Área de Docência (FAD) e a atribuição dos restantes 5\% ficaram a cargo de cada instituição (Figura 1).

Decorridos seis anos durante os quais se mobilizaram diversas iniciativas no sentido de separar as duas áreas disciplinares, o 
inevitável acaba por acontecer: a estrutura de formação imposta pelo processo de Bolonha corrige o Decreto-Lei $n^{\circ}$ 43/2007 e, com o Decreto-Lei n. ${ }^{\circ} 79 / 2014$, é estabelecido o regime jurídico da habilitação profissional para a docência, mas agora com a profissionalização em Geografia e em História em separado (Mestrado em Ensino de Geografia no $3^{\circ}$ ciclo do Ensino Básico e Secundário - MEG - e Mestrado em Ensino de História no $3^{\circ}$ ciclo do Ensino Básico e Secundário - MEH). Desta mudança resultou um ganho evidente na formação específica de ambas as áreas científicas (quer nas didáticas, quer na área de docência) e, principalmente, na formação de base, uma vez que a grande maioria dos candidatos é licenciado em Geografia ou em História, ciclos de estudo cuja conclusão exige a obtenção de 180 ECTS.

A distribuição de créditos permanece idêntica à anterior, mas confere maior flexibilidade na atribuição de ECTS entre as formações na área da docência (FAD) e educacional geral (FEG), conseguindo, desta forma, a desejada concordância entre os principios do diploma, nomeadamente quanto à promoção da formação em cada área disciplinar e à relativa margem de liberdade que as instituições de ensino superior passam a ter na atribuição de ECTS (Figura 1).

Figura 1 - Estrutura curricular dos ciclos de estudo que profissionalizam docentes em História e Geografia (MEHG), em Geografia (MEG) e em História (MEH) - distribuição de ECTS por área de formação.

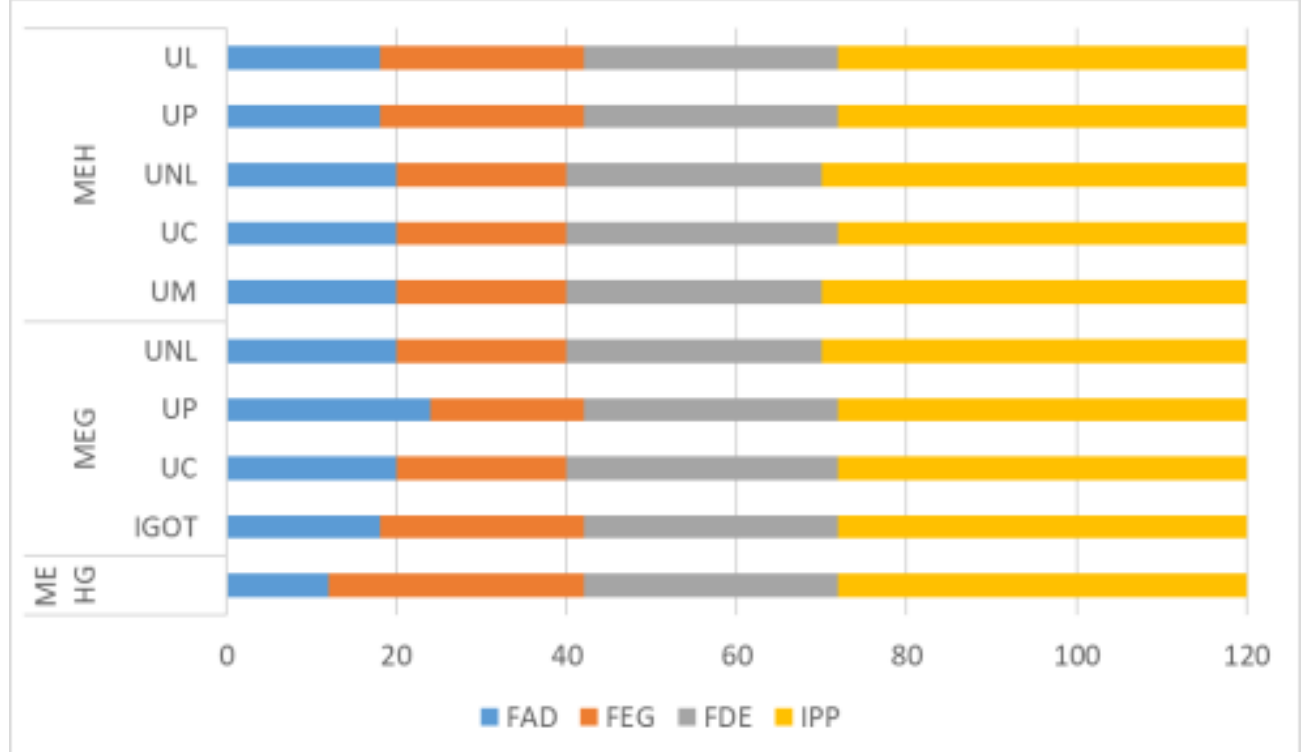

Fonte: Diário da República, $2 .^{a}$ série, N. ${ }^{\circ}$ s 52/2008, 97/2017, 140/2016, $184 / 2015, \quad 206 / 2016, \quad 172 / 2017, \quad 140 / 2016, \quad 206 / 2016,184 / 2015$, $224 / 2015$. 
Neste âmbito, registamos o aproveitamento máximo dos créditos da área da docência pelo MEG da UP em detrimento do espaço conferido à formação educacional geral. Esta, pelo contrário, manteve-se em níveis muito próximos do anterior modelo do MEHG para o caso dos MEG do IGOT e MEH da UL e UP. Ou seja, apesar do Decreto de Lei especificar que se confere a possibilidade de alargar os ECTS na formação da área de docência para que se aprofundassem os conhecimentos que farão parte dos curricula do Ensino Básico e Secundário, a maioria das Universidades não terá optado pelo aproveitamento integral dos ECTS permitidos para a formação nessa área, em favor de créditos na área educacional geral.

\section{Investigação-ação na formação de professores de Geografia e História no pós Bolonha: apresentação e discussão de resultados}

O desenvolvimento dos repositórios universitários portugueses permitiu aceder ao conjunto de relatórios de estágio em Ensino de Geografia e/ou História defendidos no quadro do Processo de Bolonha. A compilação desta informação resultou numa base com 409 títulos repartidos pela segunda década do século XXI e por cinco universidades públicas: Coimbra, Lisboa, Minho, Nova de Lisboa e Porto.

Uma primeira leitura destes registos, permite identificar um aumento significativo de relatórios registados nos primeiros anos letivos da entrada em vigor do $\mathrm{MEHG}$, com decréscimo a partir de 2013/14. Ao crescimento nesses primeiros anos, não terá sido alheio o facto de se tratar de uma profissionalização que confere grau académico de mestre - situação que não se verificava até então. Note-se que, por essa altura, o mercado de trabalho estava saturado com excesso de oferta docente, ficando muitos profissionalizados desempregados ou em situação precária durante vários anos. Em consequência, quando ocorre a separação da formação de professores em ensino de Geografia e em ensino de História a procura manteve-se escassa, verificando-se, inclusivamente, que algumas universidades que tiveram de encerrar temporariamente os seus ciclos de formação de professores por falta de alunos - como aconteceu na Universidade Nova de Lisboa - ou por não terem sido criados mestrados numa das áreas caso do MEG na Universidade do Minho.

Como se pode verificar na figura 2, a conclusão de vários relatórios de estágio do MEHG prolongou-se até aos primeiros anos de funcionamento dos sucessores monodisciplinares, altura em que o 
$\mathrm{MEH}$, comparativamente com o MEG à escala nacional, consegue segurar valores superiores de publicação de relatórios defendidos, também devido ao facto da formação de professores em História nunca ter sido suspensa como aconteceu com o MEG.

Figura 2 - Evolução do número de relatórios de estágio em ensino de Geografia e/ou História no pós-Bolonha (esquerda) e representatividade de cada um no total nacional (direita).

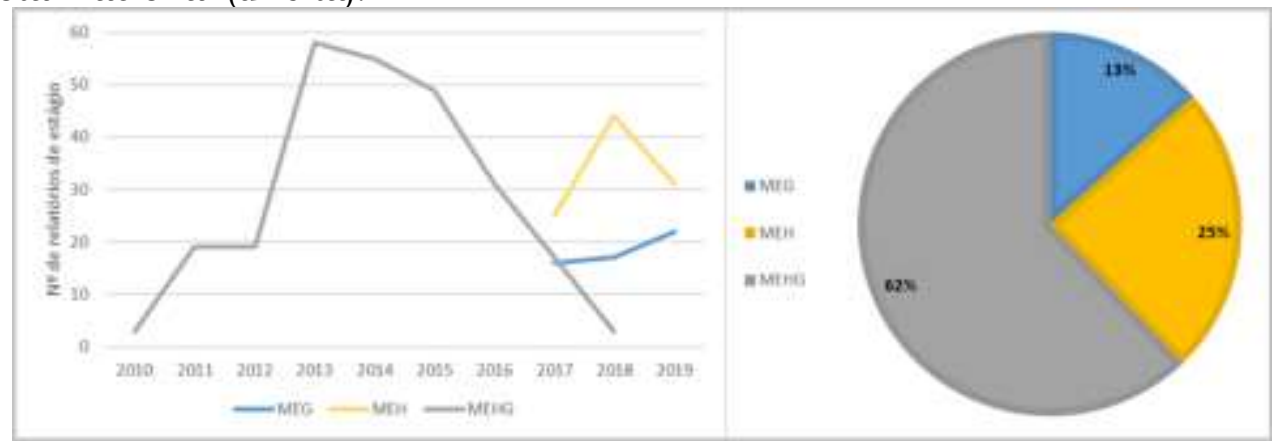

Fonte: Bases de dados dos repositórios online das universidades de Coimbra, Lisboa, Minho, Nova de Lisboa e Porto.

Com apenas três anos de existência, os segundos ciclos monodisciplinares de formação de professores de Geografia e de História representam quase $40 \%$ das publicações registadas nos repositórios portugueses das cinco universidades em observação, o que indicia uma melhoria no ritmo de crescimento se comparado com o antecessor bidisciplinar que, nesta década e durante oito anos, reuniu $62 \%$ das publicações.

Figura 3 - Evolução do número de relatórios de estágio nas universidades públicas que conferem profissionalização em ensino de Geografia e/ou História no pós-Bolonha (esquerda) e representatividade de cada universidade no total nacional (direita).

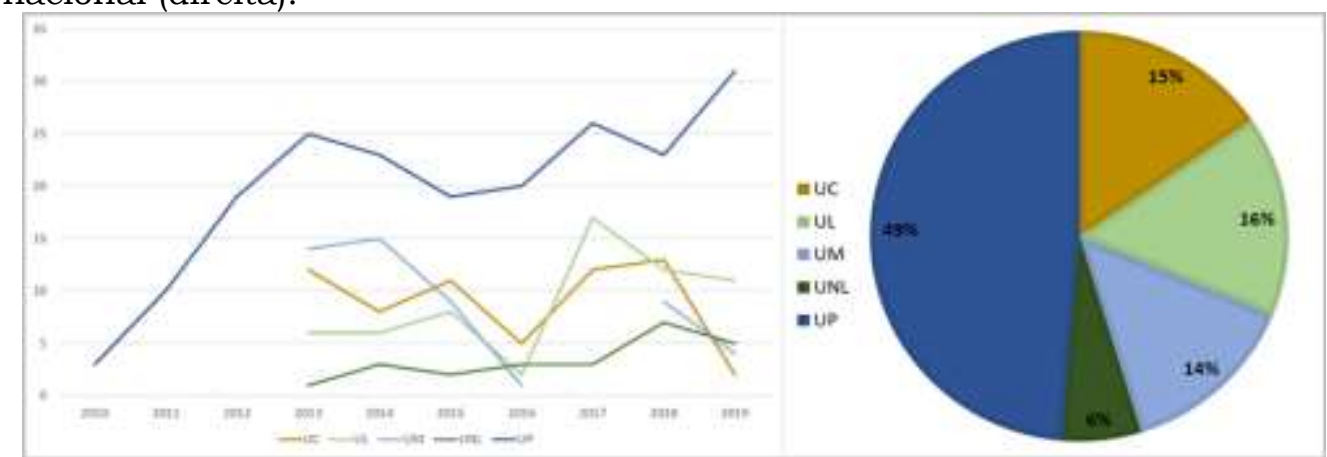

Fonte: Bases de dados dos repositórios online das universidades de Coimbra, Lisboa, Minho, Nova de Lisboa e Porto.

42 ISSN 0213-8646| E-ISSN 2530-3791 • Revista Interuniversitaria de Formación delProfesorado, 95(34.3) (2020), 33-56 
A leitura sobre a distribuição dos mestrados, bi e mono disciplinares de formação de professores de Geografia e/ou História no país ao longo desta última década, deixa perceber, por comparação com as congéneres e com alguma ressalva por eventual omissão de registo nos repositórios abertos (figura 3), valores mais elevados na Universidade do Porto ao longo de todo o período em observação. Acreditamos que este facto se deve, apenas, ao facto desta universidade oferecer um número de vagas superior - veja-se a título de exemplo, que o MEG da UP oferece 30 vagas anuais, o que corresponde ao dobro da UC ou de qualquer dos ciclos de estudo sediados em Lisboa. Apesar destas pequenas diferenças que devem ser sempre analisadas à luz da disponibilização dos relatórios defendidos por cada universidade, é interessante notar a quebra de produção, resultante de igual tendência da procura dos ciclos de estudos, verificada em 2016, claramente associada ao advento da separação da Geografia e História - situação genericamente melhor aceite pelos profissionais de ambas as áreas científicas.

A observação mais fina dos mais de quatrocentos títulos obtidos para os relatórios de estágio registados nos repositórios nacionais, processou-se através do tratamento das palavras mais utilizadas para cada um dos ciclos de estudo: MEHG, MEG e MEH.

A conjugação das imagens da figura 4, que representam as palavras mais referidas expressas graficamente em nuvens para cada mestrado em ensino em análise, com a representatividade que as quinze palavras mais referenciadas em cada ciclo de estudos têm no seu total de títulos (MEHG, MEG e MEH), expressa no gráfico da figura 5, permite perceber algumas diferenças entre o MEHG (formação bidisciplinar em História e Geografia) e os seus sucessores monodisciplinares:

- no MEHG sobressaem as palavras aprendizagem, estudo e aula;

- no MEG os destaques das palavras não são tão evidentes como nas restantes nuvens, mas podem selecionar-se algumas como ensino, experiência, aluno, didática, trabalho, aprendizagem, desenvolvimento, etc;

- no MEH a hierarquia das palavras já é mais notória, sobressaindo a didática, o aluno, a aprendizagem, entre outras. 
Figura 4 - Palavras mais referidas nos relatórios de estágio de ensino de Geografia e/ou História na última década
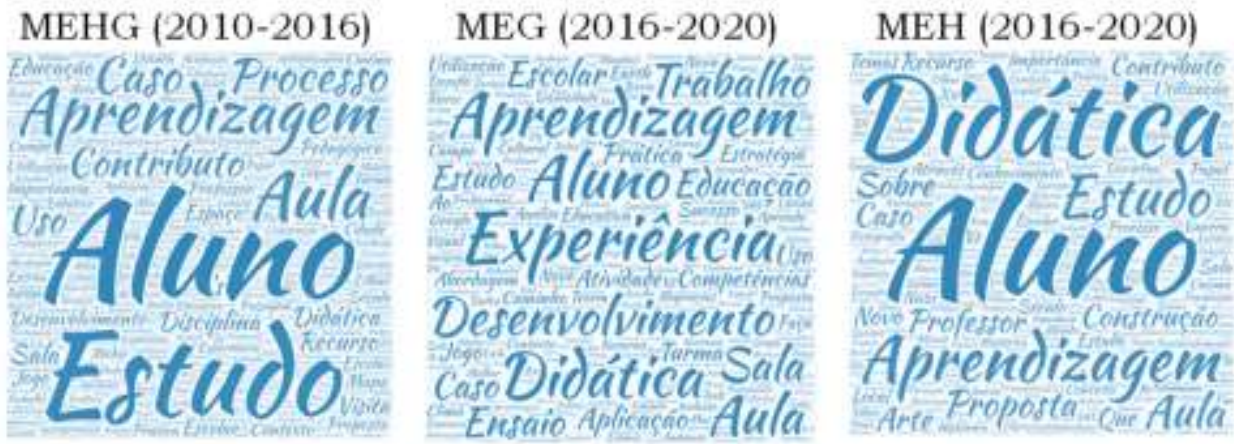

Fonte: Bases de dados dos repositórios online das universidades de Coimbra, Lisboa, Minho, Nova de Lisboa e Porto.

Note-se que as palavras "estudo" e "aula", com razoável expressão no $\mathrm{MEHG}$, tem perdido importância com o MEG e o $\mathrm{MEH}$, em favor da afirmação da "apren dizagem" e da "didática" com preocupações mais ligadas à construção do saber pelos alunos. Depois, é igualmente pertinente registar que, enquanto na formação de professores de Geografia os trabalhos experimentais, de aplicação e ensaio, constituem temáticas privilegiadas, já na formação de professores de História o foco parece orientar-se mais para temas de didática muito ligada ao uso e produção de recursos, ou ainda à utilização de fontes de que a arte e a cultura podem constituir-se como exemplos.

Figura 5 -15 palavras mais referidas em cada ciclo de estudos - peso no respetivo total de títulos

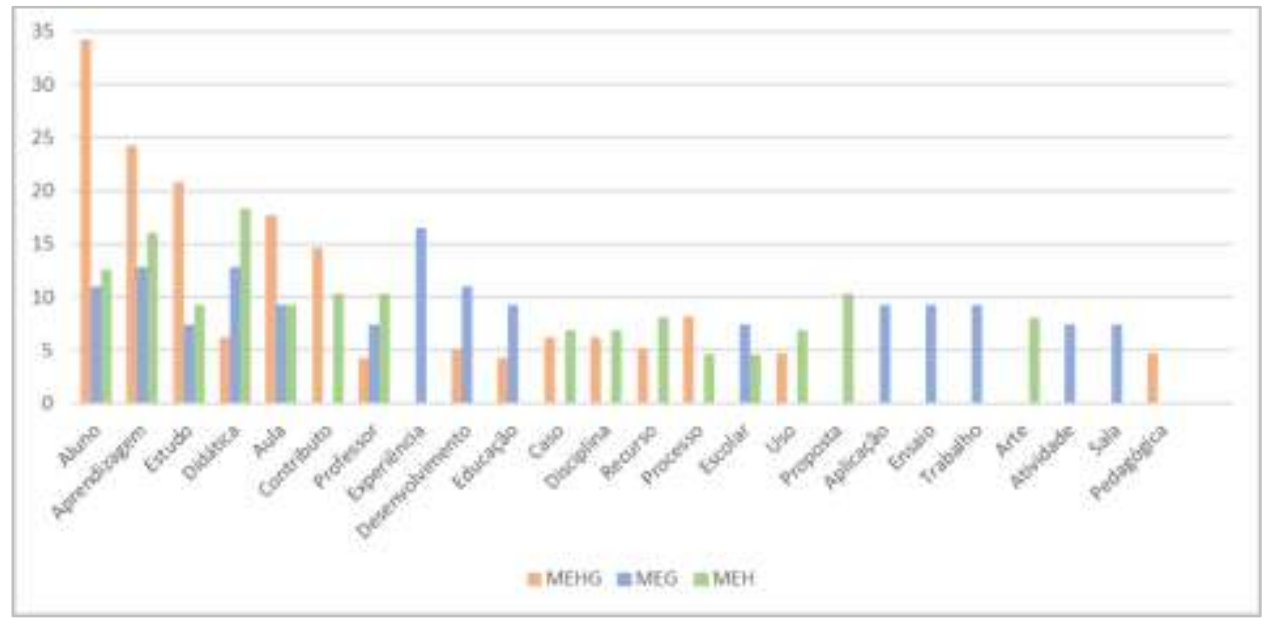

Fonte: Bases de dados dos repositórios online das universidades de Coimbra, Lisboa, Minho, Nova de Lisboa e Porto. 
Passando agora à observação das principais palavras utilizadas nos relatórios de estágio em cada uma das universidades (figura 6), é possivel observar algumas diferenças:

- os trabalhos experimentais assumem maior dimensão na UL, associando-se-lhe, como não podia deixar de ser, a aposta em temas mais ligados à didática. Este último domínio de investigação (a didática) situa-se, também, entre os mais focados na UC;

- a Universidade do Minho centra mais os temas dos seus relatórios nos "alunos", figurando a palavra "estudo" em destaque mais ligada a formulações de título do tipo "estudo de caso" ou mesmo, para o caso da Geografia, "saída de estudo", ou seja, não tanto na perspetiva de "estudo do aluno" na abordagem tradicional;

- a Universidade do Porto apresenta uma variedade significativa de palavras facilmente legiveis, mas sem destaques evidentes como as suas congéneres, juntando-se à de Lisboa para colocar o destaque os temas da "aprendizagem", ou a todas as outras para formular trabalhos que pretendem contribuir para o desenvolvimento de metodologias de trabalho em sala de aula.

Em sintese, desta primeira abordagem às palavras mais usadas nas quatro centenas de trabalhos produzidos nas cinco universidades públicas portuguesas no âmbito da formação de professores de Geografia e/ou História durante a última década (pós-Bolonha), pode confirmar-se o desenvolvimento de um caminho muito mais centrado no aluno e na aprendizagem. Neste âmbito, o desenvolvimento de estratégias de experimentação que despertem a curiosidade e a criatividade, bem como o foco na aprendizagem construtivista centrada no aluno, têm constituído razão para se avançar com diversas propostas e contributos para o apuramento do trabalho dos professores junto das novas gerações de alunos. 
Figura 6 - Palavras mais utilizadas nos relatórios de estágio do MEHG, MEG e $\mathrm{MEH}$ nas universidades portuguesas

$\mathrm{UC}$

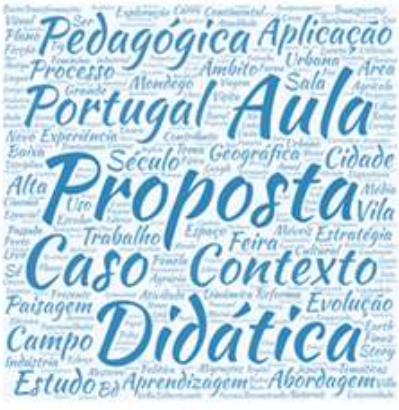

UM

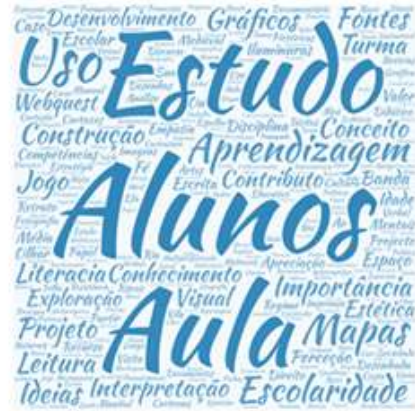

UL
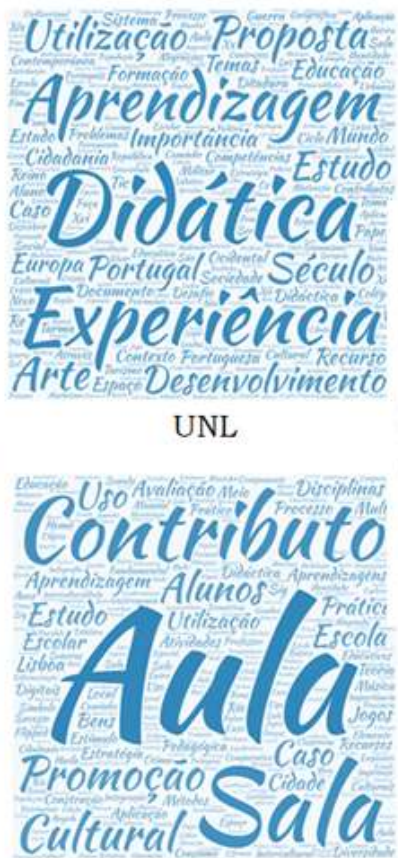

UP

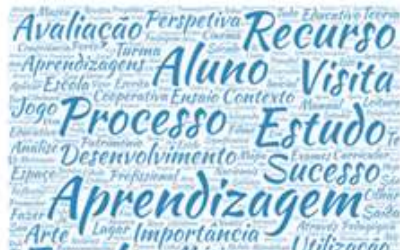
Escolart Didático Aula Prática Educaçaça Contributo

Fonte: Bases de dados dos repositórios online das universidades de Coimbra, Lisboa, Minho, Nova de Lisboa e Porto.

Do mesmo modo, a utilização frequente de palavras como experiência, aplicação, prática, uso, processo, recurso, entre outras, remete para conteúdos cada vez mais centrados em "como ensinar" e menos em "o que ensinar".

Para uma leitura mais fina sobre os relatórios de Geografia e de História desenvolvidos nas Universidades do Minho (UM) e do Porto (UP) e para se alcançar uma melhor explicitação do contributo destes relatórios de estágio em termos de investigação em Educação Histórica e Educação Geográfica, avançamos agora com a categorização por temáticas dos relatórios de estágio realizados desde 2009 a 2019. Ressalva-se que até 2014, o mestrado era bidisciplinar (MEHG), mas nem sempre os relatórios da UP integravam as duas áreas, enquanto que na UM era condição obrigatória. Com a separação dos Mestrados nas duas áreas (Decreto-Lei n. ${ }^{\circ} 79 / 2014$ ), a UM deixou de ter a área de formação em ensino de Geografia (MEG), pois só foi reestruturado o Mestrado com a área de História $(\mathrm{MEH})$, como anteriormente se explicitou, por isso, o menor número de relatórios desta área em 
relação aos de História, nesta instituição.

Para este exercício, utilizaremos uma grelha de categorização temática com os respetivos descritores para podermos validar a apreciação dos registos anteriores. Alguns dos projetos podem ser integrados em mais do que uma categoria, mas optou-se pela que era dominante em termos de temática (Quadros 1 e 2).

Quadro 1- Temáticas nos Relatórios de Estágio na área de História da UM e UP (2009-2019)

\begin{tabular}{|c|c|c|c|}
\hline Temáticas & Descritares & $\begin{array}{l}\text { UM } \\
\text { No }\end{array}$ & $\begin{array}{l}\text { UP } \\
\text { N.P }\end{array}$ \\
\hline $\begin{array}{l}\text { Literacias - Textos visuais e } \\
\text { multimodais }\end{array}$ & 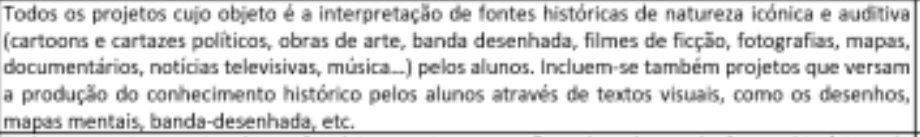 & 25 & 27 \\
\hline $\begin{array}{l}\text { Literacias - Textos verbais } \\
\text { escritos e orais }\end{array}$ & 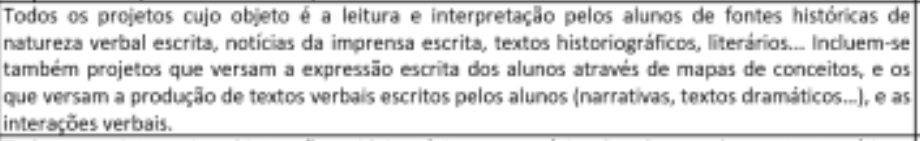 & 7 & 25 \\
\hline $\begin{array}{c}\text { Ideias tácitas, conceitos } \\
\text { estruturais/metahistóricos } \\
\text { e ou substantivos }\end{array}$ & $\begin{array}{l}\text { Todos os projetos cujos objetos ș̃o as ideias tácitas e ou prévias dos alunos sobre certas temáticas, } \\
\text { ou conceitos estruturais/metahistóricos e ou substantivos. }\end{array}$ & 14 & 13 \\
\hline Património e identidade & $\begin{array}{l}\text { Todos os projetos que versam sobre o património cultural, o meio local, a explorasaio de sitios, } \\
\text { monumentos e ou objetos, saidas de estudo, visitas in loco ou virtuais a monumentos, museus.... } \\
\text { Integram-se também projetos que relacionam o patrimánio cultural com a identidade. }\end{array}$ & 1 & 15 \\
\hline Manuais escolares & $\begin{array}{l}\text { Todos os projetos que analisam os manuais escolares ou o seu papel na aprendizagem orientada ou } \\
\text { autónoma dos alunos. }\end{array}$ & 3 & 3 \\
\hline $\begin{array}{l}\text { Web, softwares, blogs, } \\
\text { jogos didáticos }\end{array}$ & Todos os projetos que estudam a aprendizagem dos alunos feita através destes recursos educativos. & 7 & 22 \\
\hline Valor formativo da História & $\begin{array}{l}\text { Todos os projetos que versam o papel da História na compreensão de problemas do munda } \\
\text { (economia, sustentabilidade... ) e ou na promos fo de uma cidadania participativa. }\end{array}$ & 3 & 10 \\
\hline $\begin{array}{l}\text { Estratégias de } \\
\text { aprendizagem, paradigmas } \\
\text { educativos, } \\
\text { profissionalismo docente }\end{array}$ & $\begin{array}{l}\text { Todos os projetos que incidem nos processos de aprendizagem através de estratégias como a } \\
\text { aprendizagem cooperativa, a área projeto, o trabalho de pares, as interaçēes professor-aluno e } \\
\text { aluno-aluno, as inteligências múltiplas. }\end{array}$ & * & 14 \\
\hline $\begin{array}{l}\text { Curriculos, politicas } \\
\text { educativas e avaliaçảo }\end{array}$ & 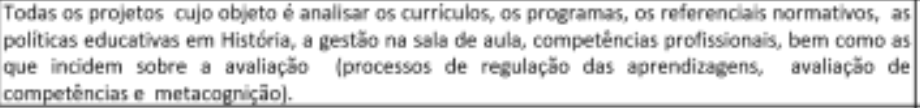 & - & 20 \\
\hline \multicolumn{2}{|l|}{ Total } & 60 & 149 \\
\hline
\end{tabular}

Fonte: Elaboração própria, adaptada da versão de Melo, M. C. (2018). As partituras iniciáticas de estudantes em Investigação e em Ensino da História, no prelo e Solé (2020).

De acordo com a proposta de categorização, adaptada de Melo (2018) e Solé (2020), apesar do número de relatórios da área de História ser substancialmente maior na UP (149) do que na UM (60), reflexo do número de vagas bastante superior da primeira instituição e de nem sempre o mestrado de ensino de História ter funcionado na UM por falta do número mínimo de alunos, algumas reflexões podem ser tecidas.

A temática dominante dos relatórios em História, em ambas as instituições, centra-se nas literacias visuais e multimodais, privilegiando-se a interpretação de fontes históricas de natureza icónica (cartoons e cartazes politicos, obras de arte, banda desenhada, filmes 
de ficção, fotografias, mapas, documentários, notícias televisivas...) e auditivas (música) pelos alunos, mas também a produção de conhecimento histórico pelos alunos através de textos visuais, como os desenhos, mapas mentais, banda-desenhada, etc.

Há também uma certa preferência pelas temáticas centradas nas literacias verbais, ou seja, na interpretação de fontes textuais, de natureza verbal escrita, notícias da imprensa escrita, textos historiográficos, literários, em que se integra nesta categoria a produção de narrativa, textos dramáticos, dramatizações e jogos de papéis, bem como as interações verbais.

Constata-se que a utilização ou produção de recursos didáticopedagógicos continua a ter uma forte expressividade no ensino da História, mas realça-se o papel do aluno na construção do conhecimento, a partir do uso de fontes diversas em suporte e linguagem, mas principalmente, a promoção de literacias visuais e textuais, focadas num ensino em que se privilegia o "como" em vez do "o que" ensinar.

Um número significativo de alunos opta por escolher temáticas relacionadas com ideias prévias/tácitas, conceitos estruturais/metahistóricos e substantivos, proporcionalmente maior na UM do que na UP, justificada em parte pela formação académica das professoras orientadoras da UM, de influência anglo-saxónica. De entre os conceitos estruturais ou metahistóricos mais frequentes, a opção recaí para a empatia histórica, significância histórica e multiperspetiva, embora a evidência histórica e a explicação histórica estejam muito presentes, integradas nas literacias, na interpretação de fontes visuais, multimodais e textuais.

Em contrapartida, na UP sobressaem as temáticas que centram a aprendizagem nos recursos tecnológicos (Web, softwares, blogs, jogos didáticos) ou focadas no currículo, políticas educativas, referenciais normativos e avaliação. Com valores significativos, na UP destacam-se ainda os relatórios com temáticas subordinadas ao património e identidade, privilegiando-se o contacto direto com o património edificado, através de visitas de estudo e saídas de campo, assim como, temáticas relacionadas com estratégias pedagógicas centradas no aluno (aprendizagem cooperativa, áreas de projeto), bem como paradigmas educativos e profissionalismo docente.

Comparativamente, as temáticas em torno da análise ou uso do manual na aprendizagem orientada ou autónoma dos alunos, ou o enfoque no valor formativo da disciplina de História, é pouco expressiva em ambas as instituições.

Esta diversidade de temáticas e a predominância de umas em relação a outras nas duas instituições, de certa forma, expressa o 
contributo e a influência, mais ou menos direta de cada orientador, que detém uma especialização diferenciada, pelo seu percurso investigativo na área do ensino de História, e direcionarem a orientação para certos enfoques e temáticas no âmbito da investigação em Educação Histórica, bem como as tendências formativas de cada instituição e os interesses dos formandos por certas temáticas.

Relativamente às temáticas dos relatórios de estágio na área de Geografia na UM e UP, procedeu-se de igual modo, adaptando-se a categorização e respetivos descritores à área de Geografia (Quadro n. ${ }^{\circ}$ 2).

Na UM há uma predominância de temáticas ao nível das literacias visuais e multimodais, em que a opção a fontes visuais geográficas, como a cartografia, os gráficos, fotografia, cartoons, recursos audiovisuais é recorrente, seguindo-se os relatórios que incidem sobre as literacias textuais, nomeadamente a leitura e interpretação de fontes geográficas de natureza verbal escrita (notícias da imprensa escrita, textos de geógrafos, memórias descritivas...) e recursos educativos suportados em instrumentos mediados pela web (webquest, aplicativos móveis, google maps e google earth, jogos digitais, entre outras ferramentas digitais). Estas tendências na UM, em parte, podem ser explicadas pela orientação destes relatórios terem sido realizadas maioritariamente por docentes da área da Didática da História, pela inexistência na UM de docentes da Didática da Geografia, embora com algum apoio dos docentes do Departamento da Geografia. 
Quadro 2- Temáticas nos Relatórios de Estágio na área de Geografia na UM e UP (2009-2019)

\begin{tabular}{|c|c|c|c|}
\hline Temáticas & Descritores & $\begin{array}{l}\text { UM } \\
\text { N.* }\end{array}$ & $\begin{array}{l}\text { UP } \\
\mathrm{N}^{\circ}\end{array}$ \\
\hline $\begin{array}{l}\text { Literacias - Textos } \\
\text { visuais, } \\
\text { multimodais }\end{array}$ & $\begin{array}{l}\text { Todos os projetos cujo objeto é a interpretaçào de fontes geográficas de natureza } \\
\text { icónica (cartoons e cartazes políticos, bandas desenhadas, fotografias, gráficos, } \\
\text { mapas, documentários, noticias televisivas...) e auditiva (musica) pelos alunos. } \\
\text { Incluem-se também projetos que versam a produçáa do conhecimento geográfico } \\
\text { pelos alunos através de textos visuais, como os desenhos e mapas mentais. }\end{array}$ & 18 & 18 \\
\hline $\begin{array}{l}\text { Literacias - Textos } \\
\text { verbais escritos ef } \\
\text { orais }\end{array}$ & $\begin{array}{l}\text { Todos as projetos cujo objeto é a leitura e interpretaçâo pelos alunos de fontes } \\
\text { geográficas de natureza verbal escrita, noticias da imprensa escrita, textos de } \\
\text { geógrafos, memórias descritivas... e/ou a produçāo de textos narrativos, mapas de } \\
\text { conceitos e as interaçóes verbais. }\end{array}$ & 8 & 14 \\
\hline $\begin{array}{l}\text { Ideias tảcitas e/ou } \\
\text { prévias e conceitos } \\
\text { substantivos } \\
\text { metageográficos. }\end{array}$ & $\begin{array}{l}\text { Todos os projetos cujos objetos sào as ideias tácitas e/ou prévias dos alunos sobre } \\
\text { certas temáticas, conceitos substantivos, conhecimento geográfico sobre um conceito } \\
\text { ou temática e conceitos estruturais/metageográficos. }\end{array}$ & 2 & 7 \\
\hline $\begin{array}{l}\text { Património, } \\
\text { paisagem, territónio } \\
\text { e identidade }\end{array}$ & $\begin{array}{l}\text { Todos os projetos que versam sobre o património natural e cultural, o meio local, a } \\
\text { exploraçāo de sitios e leitura da paisagem, saidas de estudo...Integram-se também } \\
\text { projetos que relacionam o património natural e cultural com a identidade. }\end{array}$ & - & 15 \\
\hline Manuais escolares & $\begin{array}{l}\text { Todos os projetos que analisam os manuais escolares ou } \circ \text { seu papel na } \\
\text { aprendizagem orientada ou autónoma dos alunos. }\end{array}$ & 1 & 2 \\
\hline 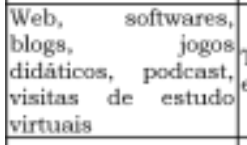 & $\begin{array}{l}\text { Todos os projetos que estudam a aprendizagem dos alunos feita através de recursos } \\
\text { educativos suportados em instrumentos mediados pela web. }\end{array}$ & 8 & 19 \\
\hline $\begin{array}{l}\text { Valor formativo da } \\
\text { Geografia }\end{array}$ & $\begin{array}{l}\text { Todos os projetos que versam o papel da Geografia na compreensão de problemas do } \\
\text { mundo, na valorizaçăo do ensino da disciplina para a formaçầo e ou na promoçấo de } \\
\text { uma cidedenia participativa. }\end{array}$ & 3 & 9 \\
\hline $\begin{array}{l}\text { Estratégias de } \\
\text { aprendizagem, } \\
\text { paradigmas } \\
\text { educativos, } \\
\text { profissionalismo } \\
\text { docente } \\
\end{array}$ & $\begin{array}{l}\text { Todos os projetos que incidem nos processos de aprendizagem através de estratégias } \\
\text { como a aprendizagem cooperativa, a área projeto, o trabalho de pares, paradigmas } \\
\text { educativos, as interaçóes professor-aluno e aluno-aluno, competéncias profissionais } \\
\text { e sobre as inteligéncias múltiplas. }\end{array}$ & - & 26 \\
\hline $\begin{array}{l}\text { Curriculos, politicas } \\
\text { educativas } \\
\text { avaliaçào }\end{array}$ & $\begin{array}{l}\text { Todas os projetos cujo objeto é analisar os curriculos, programas, referenciais } \\
\text { normativos, as políticas educativas em Geografia, bem como as que incidem sobre a } \\
\text { avaliaçâo (processos de regulaçào das aprendizagens, avaliaçăo de competéncias } \\
\text { geográficas e metacogniçào). }\end{array}$ & - & 25 \\
\hline \multicolumn{2}{|l|}{ Total } & 40 & 135 \\
\hline
\end{tabular}

Fonte: Elaboração própria, adaptada da versão de Melo, M C. (2018). As partituras iniciáticas de estudantes em Investigação e em Ensino da História, no prelo e Solé (2020).

Curiosamente na UP a maior tendência dos relatórios em Geografia focaliza-se mais nas questões em torno do profissionalismo docente, nas estratégias pedagógicas, bem como, ao nível do currículo, programas, políticas educativas e na avaliação. A segunda tendência, integra duas categorias, nomeadamente a literacia visual e multimodal e os recursos educativos tecnológicos (TIC). A terceira tendência recaí sobre o património, paisagem, território e identidade, bem como as literacias textuais e orais. 
Há uma dispersão maior nas temáticas dos relatórios da área de Geografia na UP do que na UM, a que não será alheia as especificidades de formação do corpo docente de cada instituição, aliada aos contextos educativos em que os estagiários realizaram a sua prática pedagógica.

\section{Considerações finais}

A análise das palavras utilizadas nos relatórios de estágio dos ciclos de estudo profissionalizantes em ensino de Geografia e/ou História, bem como nas temáticas escolhidas, deixa perceber a mudança que se vem operando com a ênfase colocada no aluno e nos processos de aprendizagem ativa baseadas nos princípios da procura do conhecimento e desenvolvimento holístico do ser humano que deve estar preparado para um mundo incerto.

Trata-se de um contexto de ensino e aprendizagem que pode parecer novo, mas, na verdade, prolifera em termos de reflexão há mais de, pelo menos, meio século. Inspirado em Dewey (1938), Dale (1969) defendeu a urgência de dar seguimento às atividades e experiências escolares para o mundo real, valorizando mais os resultados alcançados pelos alunos e não tanto os processos de aquisição de conhecimentos. Só partindo do concreto/real (base de uma pirâmide que Dale designou de "Pirâmide de Experiência"), é possivel alcançar, ao longo da formação escolar, níveis de sofisticação e abstração capazes de colocar o indivíduo perante a solução de problemas complexos (este estádio de desenvolvimento posiciona-se no topo da pirâmide concebida pelo autor).

Embora vivamos tempos de transição entre modelos curriculares do ensino básico e secundário mais fragmentados disciplinarmente, mas que, progressivamente, vão convergindo, seja no perfil do aluno à saída da escolaridade obrigatória ou no manejo da flexibilidade curricular onde a complexidade do mundo deve ser exercitada nos interstícios das diferentes áreas do saber tradicional, certo é que no encontro da Universidade com a Escola do ensino básico e secundário, está em primeira linha a formação de professores, neste caso de Geografia e História, e neste encontro cruzam-se gerações e saberes que atravessaram o behaviorismo, o cognitivismo, o construtivismo, o conetivismo (Siemens, 2004). Desse cruzamento, têm resultado trabalhos de investigação-ação em contexto de estágio pedagógico que vão dando conta de uma mudança lenta, mas de enorme esforço de ajuste às condições atuais: menos centrada nos padrões sociais para os quais o ensino e educação tinham respostas de rotina, e mais focada no desenvolvimento de estratégias metacognitivas para a construção de 
inteligências baseadas na vontade dos alunos. De igual modo, a experimentação parece constituir uma linha de trabalho que se impõe, cada vez mais, à transmissão do conhecimento, conhecimento este que deve ser construído pelo discente - centro de todo o processo escolar.

As universidades portuguesas preveem a formação do professor como prático, reflexivo e intelectualmente crítico, conferindo um lugar de relevo à investigação pedagógica no estágio através da construção e avaliação de um "projeto de intervenção pedagógica supervisionada" (PIPS) vertido no Relatório de Estágio (RE), que deve enquadrar-se numa visão democrática da educação. Nesta perspetiva Gago (2018a) sustenta que na formação de professores "...a universidade e a formação que esta promove, deve, por um lado, fomentar o espírito crítico e de investigação e, por outro, ampliar o seu papel como consultora de investigação e de desenvolvimento de professores..." (p. 509). Esta formação vai ao encontro do profissionalismo democrático que no quadro do desenvolvimento profissional do professor é holístico, com uma preocupação humanista - a "...articulação da ação pedagógica-educativa do professor com amplos valores e ideais da sociedade" e "a ação deste professor é orientada para a investigação e para salas de aula colaborativas que permitem vivência e experiências democráticas." (Gago, 2018b, p. 111).

Em linha com as orientações mais humanistas da educação para o século XXI, a evolução da formação de professores de Geografia e/ou História em Portugal, avaliada a partir das palavras mais utilizadas nos títulos dos trabalhos de investigação-ação realizados pelos estudantes estagiários (RE), bem como numa análise mais fina dos RE da UM e da UP através das temáticas subjacentes integradas em categorias de acordo com os respetivos descritores, ao invés de traduzir o que eventualmente se poderia esperar, isto é, o enfoque em temas de vertente tecnológica, parece que a preocupação se direciona mais para o desenvolvimento de competências do indivíduo centradas em valores e na ligação das áreas científicas em questão ao contexto de vida real dos alunos.

\section{Referências}

Akçayır, M. \& Akçayır, G. (2017). Advantages and challenges associated with augmented reality for education: A systematic review of the literature. Educational Research Review, 20, 1-11. https://doi.org/10.1016/i.edurev.2016.11.002

Cachinho, H. (2002) - Geografia Escolar: orientação teórica e práxis didáctica. Inforgeo, 15, 66-90. 
Caena, F. (2011). Literature review Quality in Teachers' continuing professional development. European Commission, 2-20.

Carver, L. B. (2016). Teacher perception of barriers and benefits in K12 technology usage. Turkish Online Journal of Educational Technology-TOJET, 15(1), 110-116. doi: 10.21125 /inted.2016.1845

Claudino, S. (2011) - A formação inicial dos professores portugueses de Geografia: por uma recontextualização disciplinar e formativa. Revista Plures Humanidades, 12(15), 13-33.

d'Oliveira Martins, G., Gomes, C., Brocardo, J., Pedroso, J., Carrillo, J. Silva, L., Encarnação, M., Horta, M., Calçada, M., Nery, R. \& Rodrigues, S. (2017). Perfil dos alunos à saída da escolaridade obrigatória. Ministério da Educação/Direção Geral da Educação.

Dale, E. (1969). Audiovisual methods in teaching (3rd ed.). New York: Dryden Press.

Darmaji, D.; Kurniawan, D.A.; Astalini, A.; Lumbantoruan, A.; Samosir, S.C. (2019) - Mobile Learning in Higher Education for The Industrial Revolution 4.0: Perception and Response of Physics Practicum. International Journal of Interactive Mobile Technologies (iJIM), 13(9), 4-20. https://doi.org/10.3991/ijim.v13i09.10948

De Vries, S., Jansen, E. \& van de Grift, W. (2013). Profiling teachers' continuing professional development and the relation with their beliefs about learning and teaching. Teaching and teacher education, 33, 78-89. https://doi.org/10.1016/j.tate.2013.02.006

Dewey, J. (1938). Experience and education. London: CollierMacmillian.

Diário da Répública (2017). Despacho n. ${ }^{\circ}$ 6478/2017. https://dre.pt/home/-/dre/107752620/details/2/maximized

Diário da Répública (2018). Decretos-Lei n. $^{\circ}$ 54/2018. https://dre.pt/web/guest/pesquisa// search/116108100/details /normal?q=DecretosLei + n.\%C2\%BA\%2054\%2F2018

Diário da Répública (2019). Lei n. ${ }^{\circ}$ 116/2019. https://dre.pt/web/guest/pesquisa/-

/ search/124680588/details /normal?q=Lei+n.\%C2\%BA\%2011 6\%2F 2019

DGE (2017a). Estratégia Nacional de Educação para a Cidadania. https://www.dge.mec.pt/estrategia-nacional-de-educacao- 


\section{para-cidadania}

DGE (2017b). Aprendizagens Essenciais. https: / / www.dge.mec.pt/aprendizagens-essenciais-0

Ertmer, P., Ottenbreit-Leftwich, A., Sadik, O., Sendurur, E. \& Sendurur, P. (2012). Teacher beliefs and technology integration practices: A critical relationship. Computers \& education, 59(2), 423-435. doi:10.1016/j.compedu.2012.02.001

Faria, E. (2004). O professor e as novas tecnologias. In Enricone, D. (Org.). Ser Professor. 4 ed. Porto Alegre: EDIPUCRS, 57-72.

Gago, M. (2018a). Ser professor de História na paleta de cores de um profissionalismo complexo. Revista Ibero-Americna de Educação Histórica (RIBEH), 1(1), 107-125. Disponivel em: "https://revistas.unila.edu.br/riaeh/index". Acesso em: 22-06-20.

Gago, M. (2018b). Ser Professor de História em tempos dificeis: início de um processo formativo. Antiteses, 11(22),507-519. Disponivel em: DOI: 10.5433/1984-3356.2018v11n22p507. Acesso em: 2206-20.

Guo, R., Dobson, T. \& Petrina, S. (2008). Digital natives, digital immigrants: An analysis of age and ICT competency in teacher education. Journal of educational computing research, 38(3), 235254. doi:10.2190/ec.38.3.a

Kirner, C. \& Zorzal, E. (2005). Aplicações educacionais em ambientes colaborativos com realidade aumentada. In Brazilian Symposium on Computers in Education (Simpósio Brasileiro de Informática na Educação-SBIE), 1(1), 114-124.

Kirschner, P. \& De Bruyckere, P. (2017). The myths of the digital native and the multitasker. Teaching and Teacher Education, 67, 135142. https://doi.org/10.1016/j.tate.2017.06.001

Kozma, R. (2003) Technology and Classroom Practices, Journal of Research on Technology in Education, 36(1), 1-14. https://doi.org/10.1080/15391523.2003.10782399

Lase, D. (2019). Education and industrial revolution 4.0. Handayani Journal PGSD FIP UNIMED, 1O(1), 48-62. doi: 10.24114/jh.v10i1

Leite, C. (2005). Percursos e tendências recentes da formação de professores em Portugal. Educação, 28(3), 371-389.

Martins, M. (2012). Formar professores no ensino superior: o caso da formação inicial de professores de Geografia na Faculdade de Letras da Universidade do Porto. In Leite, C. \& Zabalza, M. Ensino Superior: Inovação e qualidade na docência, 7870-7882. 
Melo, M. C. (2015). A formação de professores de História em Portugal: práticas pedagógicas e investigativas. Revista História Hoje, 4(7), 41-61. https://doi.org/10.20949/rhhj.v4i7.177

Mesquita, E. \& Machado, J. (2017). Formação inicial de professores em Portugal: evolução e desafios. In Neto, A. \& Fortunato, I. Educação Superior e Formação de Professores: questões atuais. São Paulo: Edições Hipótese, 97-115.

OECD (2016). Preliminary reflections and research on knowledge, skills, attitudes and values necessary for 2030. http://www.oecd.org/education/2030/.

ONU (2016). The Sustainable Development Goals Report. http://www.agenda2030.org.br/saiba_mais/publicacoes.

Ottenbreit-Leftwich, A., Glazewski, K., Newby, T. \& Ertmer, P. (2010). Teacher value beliefs associated with using technology: Addressing professional and student needs. Computers \& education, 55(3),

$1321-1335$.

https://doi.org/10.1016/i.compedu.2010.06.002

Perrenoud, P. (1999) - Construir as Competências desde a Escola. Porto Alegre: ArtMed.

Prensky, M. (2001). Digital natives, digital immigrants. On the horizon, 9(5).

Salajan, F., Schönwetter, D. \& Cleghorn, B. (2010). Student and faculty inter-generational digital divide: Fact or fiction? Computers \& Education, $55(3)$

1393-1403. https://doi.org/10.1016/i.compedu.2010.06.017

Santos, P. \& Martins, M. (2016). A Universidade do Porto e a formação inicial de professores. Revista Portuguesa de Investigação Educacional, 16, 181-199.

Siemens, G. (2004). Conectivismo - uma teoria da aprendizagem para a era digital. http://humana.social/conectivismo-una-teoria-daaprendizagem-para-a-era-digital/.

Silva, R. (1988). Curso de Geografia na Faculdade de Letras da Universidade do Porto - 1972/88. Revista da Faculdade de Letras - Geografia. I Série, Vol.4, 5-13.

Solé, G. (2020). Aprendizagem histórica e formação de professores dos anos iniciais na Universidade do Minho (Portugal): a articulação entre a prática e a investigação em educação histórica. Roteiro, 45, 1-26. https://doi.org/10.18593/r.v45i0.21997

UNESCO (2016). Repensar a educação: rumo a um bem comum mundial? Brasília: UNESCO Brasil. 
https://unesdoc.unesco.org/ark:/48223/pf0000244670

Vieira, Flávia et al. (2013). O papel da investigação na prática pedagógica dos mestrados em ensino. In. Bento Silva et al. (Orgs). Atas do XII Congresso Internacional Galego-Português de Psicopedagogia (pp. 2641-1655). Braga: CIEd, Universidade do Minho.

Wang, S., Hsu, H., Campbell, T., Coster, D. \& Longhurst, M. (2014). An investigation of middle school science teachers and students use of technology inside and outside of classrooms: considering whether digital natives are more technology savvy than their teachers. Educational Technology Research and Development, 62(6), 637-662.

West, D. (2012). Big data for education: Data mining, data analytics, and web dashboards. Governance studies at Brookings, 4(1), 1-10.

Zhou, L., Wu, S., Zhou, M., \& Li, F. (2020). 'School's Out, But Class' On', The Largest Online Education in the World Today: Taking China's Practical Exploration During The COVID-19 Epidemic Prevention and Control As an Example. But Class' On', The Largest Online Education in the World Today: Taking China's Practical Exploration During The COVID-19 Epidemic Prevention and Control As an Example (March 15). 